\title{
Reversible Expansion of Primate Mast Cell Populations In Vivo by Stem Cell Factor
}

\author{
Stephen J. Galli, * Akihiro lemura, * David S. Garlick, ${ }^{*}$ Christina Gamba-Vitalo, ${ }^{\star}$ Krisztina M. Zsebo, ${ }^{\mathbf{3}}$ and Robert G. Andrews" \\ *Departments of Pathology, Beth Israel Hospital and Harvard Medical School, Boston, Massachusetts 02215; the ${ }^{\ddagger}$ TSI Mason \\ Laboratories, Worcester, Massachusetts 01608; ${ }^{\S}$ Amgen Inc., Amgen Center, Thousand Oaks, California 91320; \\ and "Department of Pediatric Oncology, Fred Hutchinson Cancer Research Center and \\ University of Washington School of Medicine, Seattle, Washington 98104
}

\begin{abstract}
Mast cell development in mice is critically regulated by stem cell factor (SCF), the term used here to designate a product of fibroblasts and other cell types that is a ligand for the tyrosine kinase receptor protein encoded by the proto-oncogene c-kit. However, the factors which regulate the size of mast cell populations in primates are poorly understood. Here we report that the subcutaneous administration of recombinant human SCF (rhSCF) to baboons (Papio cynocephalus) or cynomolgus monkeys (Macaca fascicularis) produced a striking expansion of mast cell populations in many anatomical sites, with numbers of mast cells in some organs of rhSCF-treated monkeys exceeding the corresponding values in control monkeys by more than 100-fold. Animals treated with rhSCF did not exhibit clinical evidence of mast cell activation, and discontinuation of treatment with rhSCF resulted in a rapid decline of mast cell numbers nearly to baseline levels. These findings are the first to demonstrate that a specific cytokine can regulate mast cell development in primates in vivo. They also provide the first evidence, in any mammalian species, to indicate that the cytokinedependent expansion of tissue mast cell populations can be reversed when administration of the cytokine is discontinued. $(J$. Clin. Invest. 1993. 91:148-152.) Key words: Macaca fascicularis • mast cell hyperplasia - Papio cynocephalus • stem cell factor $\bullet$ tyrosine kinase receptors
\end{abstract}

\section{Introduction}

Mast cell development has been analyzed in more detail in mice than in any other species (for review see references 1-4). This work has demonstrated that mast cells are derived from precursors which arise in the bone marrow, circulate in the blood, and mature in virtually all vascularized tissues (1-4). Several aspects of mast cell development in mice are critically regulated by a growth factor, herein designated stem cell factor $(\mathrm{SCF})^{1}(5-7)$, which represents a ligand for the tyrosine kinase

Address correspondence to Stephen J. Galli, M.D., Director, Division of Experimental Pathology, Department of Pathology, The Beth Israel Hospital, 330 Brookline Ave., Boston, MA 02215. 1992

Received for publication 24 March 1992 and in revised form 22 July

1. Abbreviations used in this paper: rhSCF, recombinant human stem cell factor; SCF, human stem cell factor.

J. Clin. Invest.

(C) The American Society for Clinical Investigation, Inc.

$0021-9738 / 93 / 01 / 0148 / 05 \$ 2.00$

Volume 91, January 1993, 148-152 receptor encoded by the proto-oncogene c-kit (5-10). Thus, we showed that the subcutaneous administration of recombinant rat $\mathrm{SCF}^{164}$ not only locally repaired the profound mast cell deficiency expressed by $\mathrm{WCB} \mathrm{F}_{1}-S l / S l^{d}$ mice (7), which have mutations at the $S /$ locus that encodes $\operatorname{SCF}(2,4)$, but also resulted in a significant (up to 150-fold) expansion of mast cell populations at the injection site in normal mice (11). Evidence from in vivo $(7,11)$ and in vitro (12) studies indicates that the SCF-dependent expansion of mast cell populations in mice reflects the ability of this cytokine to induce mast cell proliferation and to promote mast cell survival and maturation. SCF also can increase the numbers of mast cell precursors which migrate to and/or survive at sites of SCF administration in vivo $(7,11)$, perhaps in part by promoting the c-kit receptor-dependent attachment of mast cell precursors to these sites (13).

Despite great progress in our understanding of mast cell development in mice, it has been difficult to identify cytokines which regulate mast cell development in man and other primates (for review see reference 14). Certain cytokines which clearly influence the development of some mast cell populations in mice, such as IL-3 and IL-4, have little or no effect on human mast cell development in vitro (for review see reference 14). By contrast, coculture of human umbilical cord blood leukocytes with fibroblasts augments mast cell development in vitro (14). Although fibroblasts represent a potential source of SCF (5-10), the effects of SCF on human mast cell development in vitro may vary significantly, depending on the details of the experiment. For example, preliminary evidence indicates that recombinant human SCF ( $\mathrm{rhSCF}$ ) promotes the preferential growth of mast cells from human umbilical cord blood cells (15) or human fetal liver cells (16). However, the addition of rhSCF and rhIL-3 to interphase cultures of adult human $\mathrm{CD} 4^{+}$bone marrow cells promotes the growth of multiple hematopoietic lineages including mast cells, but does not significantly change the proportion of mast cells in these cultures ( $\leq 3 \%$ of all cells) (17).

In the present study, we investigated the effects of rhSCF on mast cell development in primates by administering the cytokine directly to baboons and cynomolgus monkeys.

\section{Methods}

Experiments in baboons. The animals analyzed in the present study were two healthy juvenile male Papio cynocephalus baboons that were treated by a daily subcutaneous injection of rhSCF at 10 or $200 \mu \mathrm{g} / \mathrm{kg}$ per $d$ in the study reported in (18), which provides details concerning production of Escherichia coli-derived unmodified rhSCF (consisting of a mixture of the 164 and 165 amino acid forms), animal care, and treatment. As a control, we also analyzed a healthy juvenile male baboon which had received no subcutaneous injections. $1 \mathrm{~d}$ after the last of 28 injections of rhSCF, the baboons were anesthetized with a combi- 
nation of ketamine and xylazine and then were killed by intravenous injection of an overdose of sodium pentobarbital. Autopsies were performed immediately after the animals died. Tissues were fixed in $10 \%$ neutral buffered formalin, and 6-7- $\mu \mathrm{m}$ thick sections of paraffin-embedded tissue were stained overnight in $0.5 \%$ toluidine blue in $0.5 \mathrm{~N}$ $\mathrm{HCl}(\mathrm{pH} 0.5)$ and counterstained with $1.0 \%$ eosin in $70 \%$ ethanol for $20 \mathrm{~s}$ (19). Mast cells were counted at a magnification of 400 using a computer-assisted morphometric approach, and the results were expressed as number of mast cells per square millimeter of tissue (20).

Experiments in cynomolgus monkeys. Healthy young male or female Macaca fascicularis monkeys, which weighed $1.8-5.5 \mathrm{~kg}$ at the beginning of the study, were randomized by weight class into three groups consisting of six male and six female monkeys. Monkeys were treated on 21 consecutive days by two daily subcutaneous injections ( two injections of $0.5 \mathrm{ml} / \mathrm{kg}$ per day, given at least $6 \mathrm{~h}$ apart, of unmodified $E$. coli-derived rhSCF (as above) at 0.1 or $6.0 \mathrm{mg} / \mathrm{kg}$ per d, or vehicle alone, delivered to sites in an area clipped of hair between the shoulders and hips. Animals were housed individually, maintained under a 12-h light/dark cycle, and provided with water and standard commercially available chow supplemented with fresh produce, ad libitum. Injection sites were examined immediately after injection for possible wheal and flare responses, and monkeys were examined twice daily for abnormal clinical signs. Four male and four female animals from each group were killed by intravenous injections of an overdose of sodium pentobarbital on day 22 , whereas the remaining two male and two female animals (the "recovery group") were killed on day $36,15 \mathrm{~d}$ after the last injection of rhSCF or vehicle. Autopsies were performed immediately after death, and the tissues were fixed, stained, and analyzed for mast cell numbers as described above.

\section{Results and Discussion}

The baboon that received rhSCF at $200 \mu \mathrm{g} / \mathrm{kg}$ per d developed increased numbers of peripheral blood erythrocytes, granulocytes, lymphocytes, and monocytes; the other baboon, which received $\mathrm{rhSCF}$ at $10 \mu \mathrm{g} / \mathrm{kg}$ per d, developed no significant changes in numbers of peripheral blood erythrocytes or leukocytes (18). In comparison to a control baboon not treated with SCF, the baboons that had been treated with rhSCF, particularly the animal that received rhSCF at $200 \mu \mathrm{g} / \mathrm{kg}$ per d, exhibited high mast cell densities at several anatomical sites (Table I).

Because it was not practical to perform a thorough study of the effects of rhSCF on mast cell populations in baboons, we continued our investigation using the smaller primate, $M$. fascicularis. Treatment with rhSCF at $6.0 \mathrm{mg} / \mathrm{kg}$ per d for $21 \mathrm{~d}$ resulted in striking expansions of mast cell populations in virtually all of the tissues examined (Fig. 1 and Fig. $2 a-p$ ). The increases in mast cells compared to values in vehicle-treated control animals were especially prominent in the skin at the injection site (Fig. $2 a$ vs. $2 b$ ), spleen (Fig. $2 c$ vs. $2 d$ ), mesenteric lymph nodes (Fig. $2 e$ vs. $2 f$ ), thymus (Fig. $2 g$ vs. $2 h$ ), liver (Fig. $2 i$ vs. $2 j$ ), lung (Fig. $2 k$ vs. $2 l$ ), trachea (Fig. $2 m$ vs. $2 n$ ), and gastric mucosa (Fig. $2 o$ vs. $2 p$ ), where in some areas mast cells appeared to occupy much of the available space in the lamina propria (Fig. $2 p$ ). When the mast cell content of these organs was expressed as the number of mast cells per square millimeter, the values in animals treated with rhSCF at $6.0 \mathrm{mg} / \mathrm{kg}$ per d were 11 - to 1,500 -fold those in the control monkeys treated with vehicle (Fig. 1). Striking mast cell hyperplasia also occurred in certain tissues of monkeys treated with rhSCF at $100 \mu \mathrm{g} / \mathrm{kg}$ per d. Mast cell numbers in these animals were elevated 128 -fold in the spleen, 20 -fold in the liver, and three- to sevenfold in the dermis at the injection site, mesenteric lymph nodes, and the bone marrow (Fig. 1).
Table I. Mast Cell Density (Number per Square Millimeter) in Various Tissues of Baboons Treated with rhSCF*

\begin{tabular}{lrrrr}
\hline \multicolumn{1}{c}{ Site } & \multicolumn{3}{c}{ rhSCF } & \\
\cline { 2 - 4 } & 200 & 10 & 0 & $\begin{array}{c}\text { Area of section } \\
\text { examined }\end{array}$ \\
\hline & & $\mu g /$ kg per & & per mm \\
Lung & 136 & 16 & 6 & $6.5 \pm 0.8$ \\
Trachea & 88 & 70 & 9 & $1.2 \pm 0.4$ \\
Mesenteric lymph node & 28 & 2 & ND & 7.2 \\
Liver & 144 & 5 & ND & 4.2 \\
Spleen & 243 & 0 & ND & 4.9 \\
Stomach & & & & \\
$\quad$ Mucosa & 32 & 10 & 4 & $2.2 \pm .03$ \\
Submucosa & 79 & 26 & 6 & $1.9 \pm 0.6$ \\
$\quad$ Muscularis propria & 15 & 6 & 4 & $1.8 \pm 0.3$ \\
Jejunum & & & & \\
$\quad$ Mucosa & 9 & 3 & 0.5 & $1.8 \pm 1.0$ \\
Submucosa & 72 & 15 & 4 & $0.6 \pm 0.2$ \\
$\quad$ Muscularis propria & 4 & 6 & 5 & $0.9 \pm 0.2$ \\
& & & & \\
\hline
\end{tabular}

* The tissues were obtained for quantification of mast cell $1 \mathrm{~d}$ after the last of 28 daily subcutaneous injections of rhSCF (see Methods).

${ }^{\ddagger}$ Mean \pm SEM or, for mesenteric lymph node, liver, and spleen, mean values. ND, not determined.

At least three factors may have contributed to the differences in the effects of treatment with rhSCF on mast cell numbers in different tissues: variation in the numbers of mast cells or their precursors in different anatomical sites at the start of treatment, the nature of the organ's vasculature, and the effects of other cytokines. Studies in mice (1-4) and humans ( 14,15 , 17), indicate that the bone marrow represents a source of mast cell precursors; certain other organs, such as the skin and gastric mucosa, normally contain relatively large numbers of mature mast cells (see values for vehicle-treated monkeys in Fig. 1). Organs that have sinusoids or capillaries with a discontinuous endothelial cell lining, such as the liver, spleen, and bone marrow (21), would be expected to develop relatively high interstitial levels of SCF upon systemic administration; this type of vasculature might also favor egress of circulating mast cell precursors or mast cells. Although morphologically identifiable mast cells ordinarily are not detectable in the circulation of mammals (1-4), mast cells were present within the lumens of occasional blood vessels in the liver (Fig. $2 j$ ) or lungs (Fig. $2 l$ ) of monkeys treated with $6.0 \mathrm{mg} \mathrm{hSCF} / \mathrm{kg}$ per $\mathrm{d}$. This finding, which was not observed in vehicle-treated control monkeys, indicates that treatment with rhSCF not only increased mast cell levels in the bone marrow, but also resulted in the appearance of mast cells in the peripheral blood. We found that both primates (this study) and rats (11) treated with SCF developed striking relative increases in mast cell numbers in the spleen, liver, and bone marrow. By contrast, the midbrain of monkeys treated with rhSCF exhibited no detectable mast cells. Not only does this site ordinarily lack a significant population of mast cells (no mast mast cells were observed in the midbrain specimens from vehicle-treated animals), but the vasculature of the central nervous system is relatively impermeable to macromolecules (21). Finally, SCF exhibits synergistic effects with several hematopoietic cytokines in vitro (5); ana- 
Mast Cell Density (No./ $\left.\mathrm{mm}^{2}\right)$ in Various Tissues of Monkeys Treated with rhSCF or Vehicle

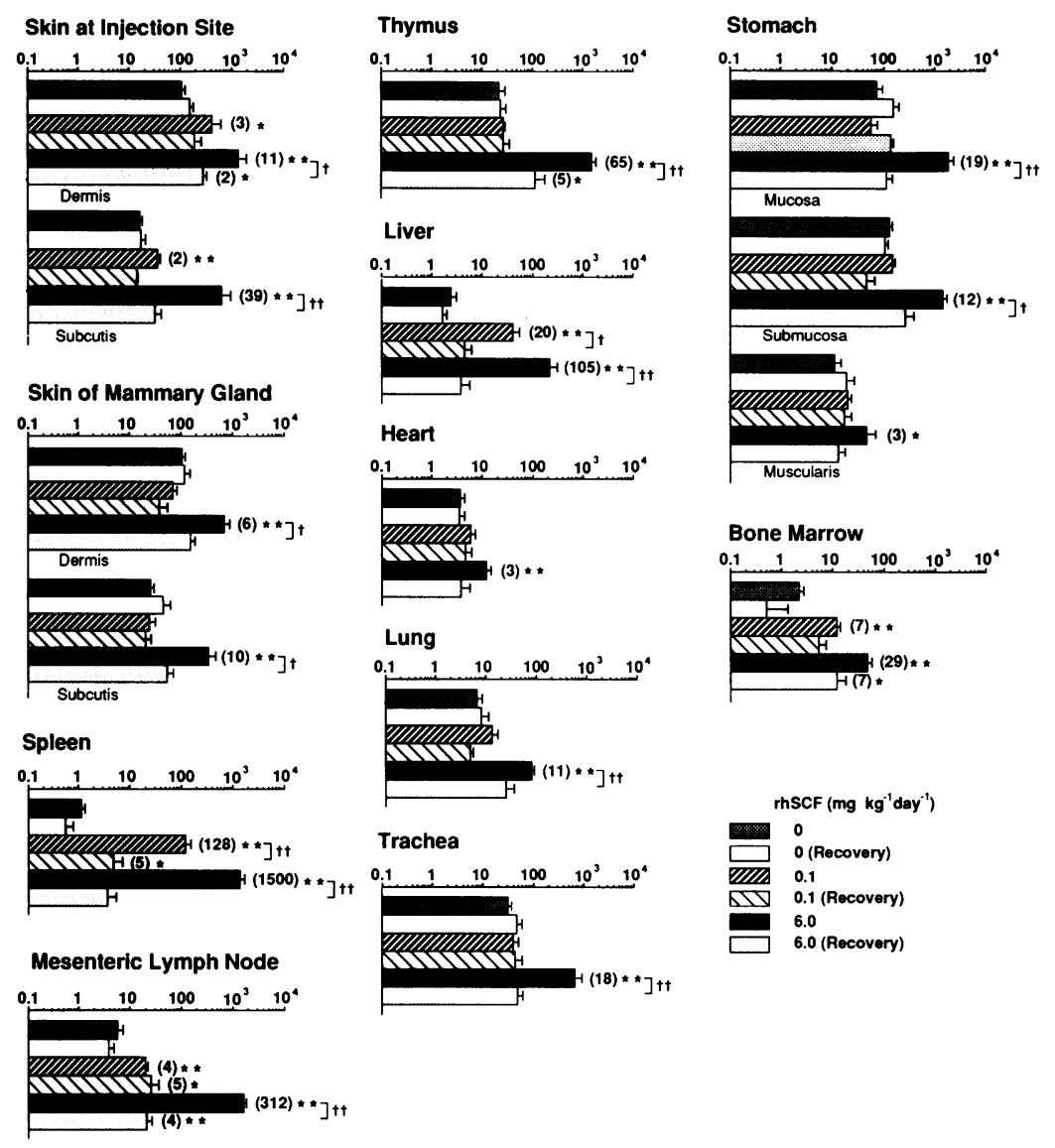

Figure 1. Numbers of mast cells (number per square millimeter of tissue, mean \pm SEM, shown on a logarithmic scale) in various organs/tissues of monkeys treated for $21 \mathrm{~d}$ with twice daily subcutaneous injections of vehicle or $\operatorname{rhSCF}(0.1$ or $6.0 \mathrm{mg} / \mathrm{kg}$ per d $)$. Monkeys were killed for autopsy $1 \mathrm{~d}$ (day 22 values) or $15 \mathrm{~d}$ (day 36 values, "recovery group") after the last injection of vehicle or rhSCF. * or ${ }^{* *}, P \leq 0.05$ or 0.01 vs. corresponding value for vehicle-treated animals; ${ }^{\dagger}$ or ${ }^{\ddagger}, P<0.05$ or 0.01 for comparisons between day 22 and day 36 values in the same treatment group (Mann-Whitney U test, two-tailed). The figures in parentheses refer to the ratio of the mean value in the indicated group to the mean value of the combined day 22 and day 36 vehicle-treated groups. The areas of tissue examined (square millimeter, mean \pm SEM) were as follows: skin at injection site, dermis: $0.22 \pm 0.02$, subcutis: $0.37 \pm 0.01$; skin of mammary gland, dermis: $0.34 \pm 0.02$, subcutis: $0.36 \pm 0.01$; spleen: $2.7 \pm 0.3$; mesenteric lymph node: $2.3 \pm 0.3$; thymus: $2.1 \pm 0.2$; liver: $3.2 \pm 0.3$; heart: $3.3 \pm 0.2$; lung $3.6 \pm 0.2$; trachea: $0.34 \pm 0.01$; stomach, mucosa: $0.65 \pm 0.08$, submucosa: $0.22 \pm 0.02$, muscularis propria: $1.00 \pm 0.2$; and bone marrow: $0.61 \pm 0.05$. tomical variation in the production of other cytokines with actions on mast cells, therefore, may also influence the effects of SCF treatment on the numbers and/or phenotype (11) of mast cells in different sites in vivo.

Discontinuation of rhSCF treatment for $15 \mathrm{~d}$ resulted in a precipitous decline in mast cell numbers which, in most anatomical sites, returned to values that were statistically indistinguishable from those in vehicle-treated control animals (Fig. 1). This finding indicates that maintenance of the greatly increased populations of mast cells present in animals treated with SCF may require continued treatment with this cytokine. It also permits speculation that local variation in levels of endogenous SCF may contribute to both the anatomical differences in tissue mast cell densities observed in normal animals and the mast cell hyperplasia observed in association with certain immunologic or pathologic responses.

Recombinant rat $\mathrm{SCF}^{164}$ can induce mediator release from some populations of mouse mast cells in vitro (22) or in vivo (23), and concentrations of rhSCF which are similar to the levels of endogenous SCF in the serum of normal subjects (3.5 $\pm 1.6 \mathrm{ng} / \mathrm{ml}, \mathrm{K}$. Zsebo et al., unpublished data) can induce mediator release from isolated human skin (24) but not lung (25) mast cells. rhSCF also can significantly augment $\mathrm{Fc}_{\boldsymbol{\epsilon}} \mathrm{RI}$ dependent mediator release from human lung (25) or skin (24) mast cells. However, the ability of mast cells to respond to a given stimulus of activation can vary significantly according to species and/or site of origin of the mast cells, and according to whether the cells are challenged in vitro or in vivo (3). Neither the baboons nor the monkeys treated with $\mathrm{rhSCF}$ in this study exhibited wheal and flare reactions at the subcutaneous injection sites, and the rhSCF-treated animals appeared well upon twice daily visual inspection. While clinical observations may not detect relatively low levels of mast cell mediator release, our observations do indicate that the rhSCF-treated animals in this study did not develop clinically obvious problems related to extensive mast cell activation.

Our findings may have implications beyond their relevance to the regulation of normal mast cell development in primates. Systemic mastocytosis is rare disorder (or group of disorders) of unknown cause which is characterized by the development of greatly expanded populations of mast cells in a distribution very similar to that observed in monkeys treated with high doses of rhSCF ( for review see references 26, 27). Patients with systemic mastocytosis, like some of our monkeys treated with rhSCF at $6.0 \mathrm{mg} / \mathrm{kg}$ per d, also can exhibit occasional mast cells in the peripheral blood (26). While our findings raise the possibility that the excessive or dysregulated production of SCF could produce findings similar to those observed in some cases of systemic mastocytosis, analysis of the serum of patients with systemic mastocytosis has not demonstrated significant elevations in levels of SCF (Zsebo, K., and D. D. Metcalfe, unpublished data). Alternatively, some cases of mastocytosis might reflect changes that result in the constitutive activation of mast cell c-kit receptors (28) or that increase the receptor's sensitiv- 

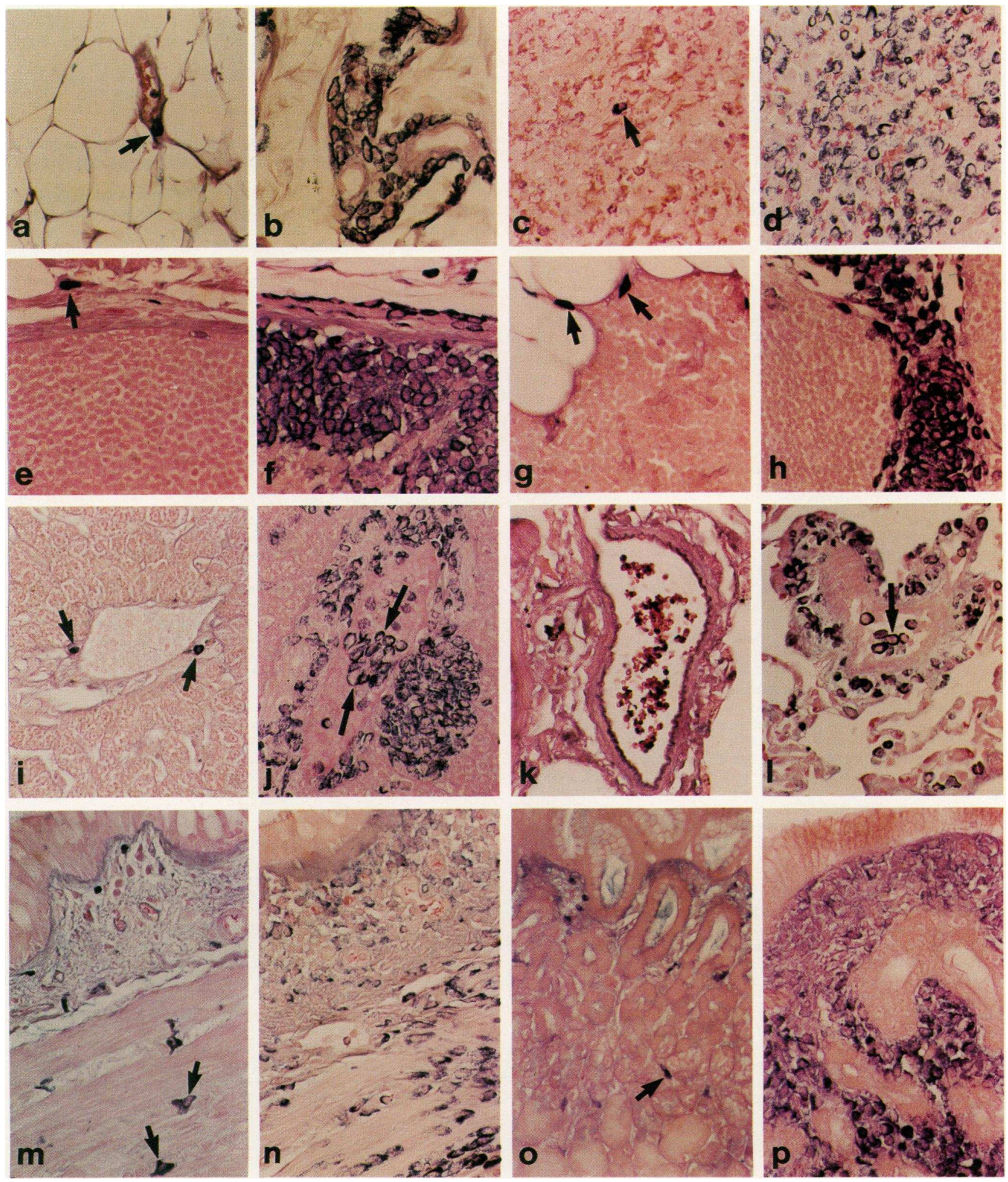

Figure 2. Histologic sections of tissues of a monkey treated for $21 \mathrm{~d}$ with twice daily subcutaneous injections of vehicle $(a, c, e, g, i, k, m$, and $o)$ and a monkey treated for $21 \mathrm{~d}$ with twice daily subcutaneous injections of rhSCF at $6.0 \mathrm{mg} / \mathrm{kg}$ per d, $(b, d, f, h, j, l, n$, and $p)$. Note the striking differences in the numbers of mast cells (cells with purple-black appearing cytoplasmic granules, some indicated by short arrows) in the sections from vehicle- or rhSCF-treated animals. All sections $\times 250$. $(a, b)$ Subcutaneous tissue at injection site; $(c, d)$ spleen; $(e, f)$ mesenteric lymph node; $(g, h)$ thymus; $(i, j)$ liver (note cluster of mast cells [long arrows] within a blood vessel in $[j]) ;(k, l)$ lung (note mast cells $[$ long arrow] within a blood vessel in $[l] ;(m, n)$ trachea; $(o, p)$ gastric mucosa. 
ity to SCF. Although it is not yet clear whether the c-kit receptor or its ligand have any role in disorders associated with the abnormal proliferation of mast cells, understanding of the pathogenetic mechanisms responsible for some of the clinical problems exhibited by patients with systemic mastocytosis would be facilitated by a suitable animal model for this disorder. Monkeys treated chronically with high doses of rhSCF may provide such a model system. Such monkeys may also be useful for analyzing the contributions of mast cells to a wide variety of other pathological conditions or physiological responses.

\section{Acknowledgments}

This work was supported by United States Public Health Service grants AI-22674, AI-23990, CA-28834, AI-85003, RR-00166, CA-39492, and CA-15704, Amgen, Inc., and the Beth Israel Hospital Pathology Foundation.

\section{References}

1. Kitamura, Y., M. Yokoyama, H. Matsuda, T. Ohno, and K. J. Mori. 1981. Spleen colony-forming cell as common precursor for tissue mast cells and granulocytes. Nature (Lond.). 291:159-160.

2. Kitamura, Y., H. Nakayama, and J. Fujita. 1989. Mechanism of mast cell deficiency in mutant mice of $W / W^{v}$ and $S l / S l^{d}$ genotype. In Mast Cell and Basophil Differentiation and Function in Health and Disease. S. J. Galli and K. F. Austen, editors. Raven Press, Ltd., New York. 15-25.

3. Galli, S. J. 1990. New insights into "the riddle of the mast cells:" microenvironmental regulation of mast cell development and phenotypic heterogeneity. Lab. Invest. 62:5-33.

4. Galli, S. J., E. N. Geissler, B. K. Wershil, J. R. Gordon, M. Tsai, and I. Hammel. 1992. Insights into mast cell development and function derived from analyses of mice carrying mutations at beige, $\mathrm{W} / \mathrm{c}-k i t$ or $S / / S C F$ (c-kit ligand) loci. In The Role of the Mast Cell in Health and Disease. M. A. Kaliner and D. D. Metcalfe, editors. Marcel Dekker, Inc., New York. 129-202.

5. Zsebo, K. M., J. Wypych, I. K. McNiece, H. S. Lu, K. A. Smith, S. B. Karkare, R. K. Sachdev, V. N. Yuschenkoff, N. C. Birkett, L. R. Williams, et al. 1990. Identification, purification, and biological characterization of hematopoietic stem cell factor from buffalo rat liver-conditioned medium. Cell. 63:195201.

6. Martin, F. H., S. V. Suggs, K. E. Langley, H. S. Lu, J. Ting, K. H. Okino, C. F. Morris, I. K. McNiece, F. W. Jacobsen, E. A. Mendiaz, et al. 1990. Primary structure and functional expression of rat and human stem cell factor DNAs. Cell. 63:203-211.

7. Zsebo, K. M., D. A. Williams, E. N. Geissler, V. C. Broudy, F. H. Martin, H. L. Atkins, R.-Y. Hsu, N. C. Birkett, K. H. Okino, D. C. Murdock, et al. 1990. Stem Cell Factor (SCF) is encoded at the $S /$ locus of the mouse and is the ligand for the c-kit tyrosine kinase receptor. Cell. 63:213-224.

8. Williams, D. E., J. Eisenman, A. Baird, C. Rauch, K. V. Ness, C. J. March, L. S. Park, U. Martin, D. Mochizuki, H. S. Boswell, et al. 1990. Identification of a ligand for the c-kit proto-oncogene. Cell. 63:167-174.

9. Huang, E., K. Nocka, D. R. Beier, T.-Y. Chu, J. Buck, H.-W. Lahm, D. Wellner, P. Leder, and P. Besmer. 1990. The hematopoietic growth factor KL is encoded at the $S /$ locus and is the ligand of the c-kit receptor, the gene product of the $W$ locus. Cell. 63:225-233.

10. Flanagan, J. G., and P. Leder. 1990. The c-kit ligand: a cell surface molecule altered in steel mutant fibroblasts. Cell. 63:185-194.

11. Tsai, M., L. Shih, G. F. J. Newlands, T. Takeishi, K. E. Langley, K. M.
Zsebo, H. R. P. Miller, E. N. Geissler, and S. J. Galli. 1991. The rat c-kit ligand, stem cell factor, induces the development of connective tissue-type and mucosal mast cells in vivo. Analysis by anatomical distribution, histochemistry, and protease phenotype. J. Exp. Med. 174:125-131.

12. Tsai, M., T. Takeishi, H. Thompson, K. E. Langley, K. M. Zsebo, D. D. Metcalfe, E. N. Geissler, and S. J. Galli. 1991. Induction of mast cell proliferation, maturation and heparin synthesis by the rat c-kit ligand, stem cell factor. Proc. Natl. Acad. Sci. USA. 88:6382-6386.

13. Flanagan, J. G., D. C. Chan, and P. Leder. 1991. Transmembrane form of the kit ligand growth factor is determined by alternative splicing and is missing in the $S l^{d}$ mutant. Cell. 64:1025-1035.

14. Furitsu, T., H. Saito, A. M. Dvorak, L. B. Schwartz, A.-M. A. Irani, J. F. Burdick, K. Ishizaka, and T. Ishizaka. 1989. Development of human mast cells in vitro. Proc. Natl. Acad. Sci. USA. 86:10039-10043.

15. Ishizaka, T., T. Furitsu, H. Mitsui, M. Takei, M. A. Koszloski, A.-M. A. Irani, L. B. Schwartz, A. M. Dvorak, K. M. Zsebo, and S. Gillis. 1992. Development of human mast cells from umbilical cord blood cells by human and murine c-kit ligand. FASEB (Fed. Am. Soc. Exp. Biol.) J. 6:A1403 (Abstr.)

16. Nillson, G., A. A. Irani, T. Ishizaka, and L. B. Schwartz. 1992. Human recombinant stem cell factor (SCF), the ligand for c-kit, induces development of human mast cells whereas IL-3 induces basophil-like cells from fetal liver cells (FLC). FASEB (Fed. Am. Soc. Exp. Biol.) J. 6:A1722 (Abstr.)

17. Kirschenbaum, A. S., J. P. Goff, S. W. Kessler, J. M. Mican, K. M. Zsebo, and D. D. Metcalfe. 1992. Effect of IL-3 and Stem Cell Factor on the appearance of human basophils and mast cells from CD34+ pluripotent progenitor cells. $J$. Immunol. 148:772-777.

18. Andrews, R. G., G. H. Knitter, S. H. Bartelmez, K. E. Langley, D. Farrar, R. W. Hendren, F. R. Appelbaum, I. D. Bernstein, and K. M. Zsebo. 1991. Recombinant human stem cell factor, a c-kit ligand, stimulates hematopoiesis in primates. Blood. 78:1975-1980.

19. Wingren, U., and L. Enerbäck. 1983. Mucosal mast cells of the rat intestine: a re-evaluation of fixation and staining properties, with special reference to protein blocking and solubility of the granular glycosaminoglycan. Histochem. J. 15:571-582.

20. Wershil, B. K., T. Murakami, and S. J. Galli. 1988. Mast cell-dependent amplification of an immunologically nonspecific inflammatory response. Mast cells are required for the full expression of cutaneous acute inflammation induced by phorbol 12-myristate 13-acetate. J. Immunol. 140:2356-2360.

21. Junqueira, L. C., J. Carnevo, and J. A. Long. 1986. Basic Histology. Appleton-Century-Crofts, East Norwalk, CT. 255-269.

22. Galli, S. J., M. T. Tsai, K. E. Langley, K. M. Zsebo, and E. N. Geissler. 1991. Stem cell factor (SCF), a ligand for c-kit, induces mediator release from some populations of mouse mast cells. FASEB (Fed. Am. Soc. Exp. Biol.) J. 5:A1092 (Abstr.)

23. Wershil, B. K., M. Tsai, E. N. Geissler, K. M. Zsebo, and S. J. Galli. 1992. The rat c-kit ligand, stem cell factor, induces c-kit receptor-dependent mouse mast cell activation in vivo. Evidence that signaling through the c-kit receptor can induce expression of cellular function. J. Exp. Med. 175:245-255.

24. Columbo, M., E. M. Horowitz, L. M. Botana, D. W. MacGlashan, Jr., B. S. Bochner, S. Gillis, K. M. Zsebo, S. J. Galli, and L. M. Lichtenstein. 1992. The recombinant human c-kit receptor ligand, rhSCF, induces mediator release from human cutaneous mast cells and enhances IgE-dependent mediator release from both skin mast cells and peripheral blood basophils. J. Immunol. 149:599608 .

25. Bischoff, S. C., and C. A. Dahinden. 1992. c-kit ligand: a unique potentiator of mediator release by human lung mast cells. J. Exp. Med. 175:237-244.

26. Travis, W. D., C. Y. Li, E. J. Bergstralh, L. T. Yam, and R. G. Swee. 1988. Systemic mast cell disease: analysis of 58 cases and literature review. Medicine (Baltimore). 67:345-368.

27. Metcalfe, D. D. 1991. The liver, spleen, and lymph nodes in mastocytosis. J. Invest. Dermatol. 96:45S-46S.

28. Rottapel, R., M. Reedijk, D. E. Williams, S. D. Lyman, D. M. Anderson, T. Pawson, and A. Bernstein. 1991. The Steel/ $W$ transduction pathway: kit autophosphorylation and its association with a unique subset of cytoplasmic signaling proteins is induced by the Steel factor. Mol. Cell. Biol. 11:3043-3051. 